\title{
Association Between Age at Diabetes Onset and Subsequent Risk of Dementia
}

Citation for published version (APA):

Amidei, C. B., Fayosse, A., Dumurgier, J., Machado-Fragua, M. D., Tabak, A. G., van Sloten, T., Kivimaki, M., Dugravot, A., Sabia, S., \& Singh-Manoux, A. (2021). Association Between Age at Diabetes Onset and Subsequent Risk of Dementia. JAMA-Journal of the American Medical Association, 325(16), 1640-1649. https://doi.org/10.1001/jama.2021.4001

Document status and date:

Published: 27/04/2021

DOI:

10.1001/jama.2021.4001

Document Version:

Publisher's PDF, also known as Version of record

Document license:

Taverne

Please check the document version of this publication:

- A submitted manuscript is the version of the article upon submission and before peer-review. There can be important differences between the submitted version and the official published version of record.

People interested in the research are advised to contact the author for the final version of the publication, or visit the DOI to the publisher's website.

- The final author version and the galley proof are versions of the publication after peer review.

- The final published version features the final layout of the paper including the volume, issue and page numbers.

Link to publication

\footnotetext{
General rights rights.

- You may freely distribute the URL identifying the publication in the public portal. please follow below link for the End User Agreement:

www.umlib.nl/taverne-license

Take down policy

If you believe that this document breaches copyright please contact us at:

repository@maastrichtuniversity.nl

providing details and we will investigate your claim.
}

Copyright and moral rights for the publications made accessible in the public portal are retained by the authors and/or other copyright owners and it is a condition of accessing publications that users recognise and abide by the legal requirements associated with these

- Users may download and print one copy of any publication from the public portal for the purpose of private study or research.

- You may not further distribute the material or use it for any profit-making activity or commercial gain

If the publication is distributed under the terms of Article $25 \mathrm{fa}$ of the Dutch Copyright Act, indicated by the "Taverne" license above, 
JAMA | Original Investigation

\section{Association Between Age at Diabetes Onset and Subsequent Risk of Dementia}

Claudio Barbiellini Amidei, MD; Aurore Fayosse, MSc; Julien Dumurgier, PhD; Marcos D. Machado-Fragua, PhD; Adam G. Tabak, PhD; Thomas van Sloten, PhD; Mika Kivimäki, PhD; Aline Dugravot, MSc; Séverine Sabia, PhD; Archana Singh-Manoux, PhD

IMPORTANCE Trends in type 2 diabetes show an increase in prevalence along with younger age of onset. While vascular complications of early-onset type 2 diabetes are known, the associations with dementia remains unclear.

OBJECTIVE To determine whether younger age at diabetes onset is more strongly associated with incidence of dementia.

DESIGN, SETTING, AND PARTICIPANTS Population-based study in the UK, the Whitehall II prospective cohort study, established in 1985-1988, with clinical examinations in 1991-1993, 1997-1999, 2002-2004, 2007-2009, 2012-2013, and 2015-2016, and linkage to electronic health records until March 2019. The date of final follow-up was March 31, 2019.

EXPOSURES Type 2 diabetes, defined as a fasting blood glucose level greater than or equal to $126 \mathrm{mg} / \mathrm{dL}$ at clinical examination, physician-diagnosed type 2 diabetes, use of diabetes medication, or hospital record of diabetes between 1985 and 2019.

MAIN OUTCOMES AND MEASURES Incident dementia ascertained through linkage to electronic health records.

RESULTS Among 10095 participants (67.3\% men; aged 35-55 years in 1985-1988), a total of 1710 cases of diabetes and 639 cases of dementia were recorded over a median follow-up of 31.7 years. Dementia rates per 1000 person-years were 8.9 in participants without diabetes at age 70 years, and rates were 10.0 per 1000 person-years for participants with diabetes onset up to 5 years earlier, 13.0 for 6 to 10 years earlier, and 18.3 for more than 10 years earlier. In multivariable-adjusted analyses, compared with participants without diabetes at age 70, the hazard ratio (HR) of dementia in participants with diabetes onset more than 10 years earlier was $2.12(95 \% \mathrm{Cl}, 1.50-3.00), 1.49(95 \% \mathrm{Cl}, 0.95-2.32)$ for diabetes onset 6 to 10 years earlier, and $1.11(95 \% \mathrm{Cl}, 0.70-1.76)$ for diabetes onset 5 years earlier or less; linear trend test $(P<.001)$ indicated a graded association between age at onset of type 2 diabetes and dementia. At age 70, every 5 -year younger age at onset of type 2 diabetes was significantly associated with an $\mathrm{HR}$ of dementia of $1.24(95 \% \mathrm{Cl}, 1.06-1.46)$ in analyses adjusted for sociodemographic factors, health behaviors, and health-related measures.

CONCLUSIONS AND RELEVANCE In this longitudinal cohort study with a median follow-up of 31.7 years, younger age at onset of diabetes was significantly associated with higher risk of subsequent dementia.

JAMA. 2021;325(16):1640-1649. doi:10.1001/jama.2021.4001
Supplemental content

CME Quiz at

jamacmelookup.com
Author Affiliations: Author affiliations are listed at the end of this article.

Corresponding Author: Archana Singh-Manoux, PhD, EpiAgeing, Université de Paris, Inserm U1153, 10 Avenue de Verdun, 75010 Paris France (archana.singh-manoux@ inserm.fr). 
$\mathrm{T}$ he prevalence of type 2 diabetes has risen due to population aging, increasing obesity, physical inactivity, and energy-dense diets. ${ }^{1}$ More than $90 \%$ of individuals with diabetes have type 2 diabetes, and among these individuals, there is considerable potential for disease management to reduce risk of subsequent health complications. Diabetes is associated with higher risk of cardiovascular morbidity and mortality, ${ }^{2}$ along with mortality from nonvascular conditions. ${ }^{3}$

While the role of type 2 diabetes for cardiovascular outcomes is established, its importance for neurocognitive outcomes remains uncertain. Large-scale, multicohort metaanalyses published in 2012, ${ }^{4} 2016,{ }^{5} 2017,{ }^{6}$ and $2019^{7,8}$ have shown the risk ratio of the association between diabetes and dementia to be between 1.43 and $1.62 .{ }^{4-8}$ The primary limitation of these studies was not being able to examine the importance of age at diabetes onset for dementia, particularly as younger age at type 2 diabetes onset is known to be important for mortality and cardiovascular outcomes. ${ }^{9-11}$ The most recent review of 12 modifiable risk factors for dementia carefully separated risk factors in early- ( $<45$ years), mid- (45-65 years), and late-life ( $>65$ years) age groups; diabetes was judged to be a risk factor only in late life, associated with a populationattributable fraction of $1.1 \%{ }^{12}$

Given evidence of younger age at onset of diabetes,${ }^{13}$ the primary objective of this study was to examine the association between age at onset of diabetes and incident dementia using data spanning midlife to old age.

\section{Methods}

Study Population

The Whitehall II study is an ongoing cohort study established in 1985-1988 among 10308 persons (6895 men and 3413 women, aged 35-55 years) employed in London-based government departments. ${ }^{14}$ Written informed consent from participants and research ethics approvals were renewed at each contact; the most recent approval was from the University College London Hospital Committee on the Ethics of Human Research (reference number 85/0938). The age, sex, and race distribution in the study reflects that in the target population; for race, it also reflects the UK population distribution in the 1980s. Since baseline, follow-up clinical examinations have taken place approximately every 4 to 5 years (1991-1993, 1997-1999, 2002-2004, 2007-2009, 2012-2013, and 2015-2016) with each wave taking 2 years to complete, with ongoing data collection at the 2020-2021 wave. In addition to data collection within the study, data over the follow-up were available using linkage to electronic health records of the UK National Health Service (NHS) for all but 10 of the 10308 participants recruited to the study (eFigure 1 in the Supplement). The NHS provides most of the health care in the UK, including inpatient and outpatient care, and record linkage is undertaken using a unique NHS identifier held by all UK residents. Data from linked records were updated on an annual basis until March 31, 2019.

\section{Key Points}

Question What is the association between age at onset of type 2 diabetes and subsequent risk of dementia?

Findings In this prospective cohort study of 10095 participants, younger age at onset of type 2 diabetes was significantly associated with higher risk for incident dementia; at age 70 , the hazard ratio for every 5 -year earlier age at type 2 diabetes onset was 1.24 .

Meaning Younger age at diabetes onset was associated with higher risk of subsequent dementia.

\section{Primary Exposure}

Type 2 Diabetes

At 7 clinical assessments between 1985 and 2016, venous blood samples were taken in the morning after at least 8 hours of fasting or at least 5 hours fasting after a light, fat-free breakfast; fasting glucose was measured using the glucoseoxidase method. ${ }^{15}$ At the clinical examination, data were also collected on self-reported physician-diagnosed type 2 diabetes and prescription of diabetes medication (insulin or oral glucose-lowering drugs) in the period between 2 clinical assessments. In addition, data on hospital-based consultations for type 2 diabetes were available via linkage to the national Hospital Episode Statistics (HES) database over the entire follow-up on all participants, irrespective of their participation in study clinical assessments. Type 2 diabetes was defined using measures of fasting glucose $(126 \mathrm{mg} / \mathrm{dL}$ [to convert to $\mathrm{mmol} / \mathrm{L}$, multiply by 0.0555 ]) at the clinical examination, use of diabetes medication, reported physiciandiagnosed diabetes, or record of diabetes in the HES database (International Classification of Diseases, Tenth Revision [ICD-10] code E11).

\section{Secondary Exposures}

Three exposures were assessed in participants free of type 2 diabetes: the Finnish Diabetes Risk Score (FINDRISC), fasting glucose, and prediabetes.

The FINDRISC ${ }^{16}$ was used to calculate the risk of diabetes based on the original scoring method (eTable 1 in the Supplement), which included age, family history of diabetes, fruit and vegetable consumption, physical activity, medication for high blood pressure, personal history of high blood glucose (clinical examination), body mass index (BMI; calculated as weight in kilograms divided by height in meters squared), and measured waist circumference. The FINDRISC ranges from 0 to 26 (higher scores reflect higher risk of diabetes when the score is used as a continuous variable, as in these analyses).

In addition to continuous measures of fasting glucose, prediabetes was defined according to the American Diabetes Association criteria (fasting glucose between $100-125 \mathrm{mg} / \mathrm{dL}$ ) and in additional analysis using World Health Organization criteria $(110-125 \mathrm{mg} / \mathrm{dL})$.

\section{Outcome}

Dementia cases were ascertained by linkage to 3 national registers (the HES database, the Mental Health Services Data Set, 
and the Office for National Statistics Mortality Register) until March 31, 2019, using the unique NHS identification number. All-cause dementia was identified based on ICD-10 codes (F00-F03, F05.1, G30, and G31). The sensitivity of dementia was $78 \%$ and the specificity was $92 \%$ using HES data. ${ }^{17}$ The sensitivity in our study is likely to be further improved due to use of the Mental Health Services Data Set, a national database that contains information on dementia for persons in contact with mental health services in hospitals, outpatient clinics, and the community. ${ }^{18}$ Cause-specific mortality data were drawn from the NHS national mortality register. Date of dementia was set at the first record of dementia diagnosis using all 3 databases.

\section{Covariates}

Sociodemographic

Variables included age, sex, race (assessed by questionnaire using the response categories White, South Asian, Black, Other), and education ( $\leq$ partial secondary school, high school diploma, zuniversity).

\section{Health Behaviors}

Variables included smoking (never smoker, current smoker, former smoker), alcohol consumption (none in the previous week, 1-14 units/week, >14 units/week; 1 unit reflects $10 \mathrm{~mL}$ [8 g] of pure alcohol), time spent in moderate and vigorous physical activity, and frequency of fruit and vegetable consumption (less than daily, once daily, $\geq 2$ times/day).

\section{Health-Related Variables}

These variables included hypertension (systolic/diastolic blood pressure $\geq 140 / 90 \mathrm{~mm} \mathrm{Hg}$ or use of antihypertensive medication), BMI ( $<25,25-29.9$, and $\geq 30)$, use of antidepressants and cardiovascular disease (CVD) medication (diuretics, $\beta$-blockers, RAAS inhibitors, calcium channel blockers or other antihypertensives, lipid-modifying drugs, nitrates, and antiplatelets).

Apolipoprotein E (APOE) genotyping DNA was extracted from whole blood samples and examined on a 7900HT analyzer (Applied Biosystems).

\section{Cardiovascular Disease}

Variables included coronary heart disease (CHD), heart failure, and stroke. CHD was identified by 12-lead resting electrocardiogram recording coded using the Minnesota system and linkage to the HES database (ICD-10 codes I20-I25). Heart failure (ICD-10 code I50) and stroke (ICD-10 codes I60-I64) were determined using linkage to the HES database.

\section{Statistical Analysis}

Data on exposure (diabetes, prediabetes, fasting glucose, and FINDRISC) at ages 55, 60, 65, and 70 years were extracted using the total span of the study (eFigure 1 in the Supplement). The analyses were undertaken using Cox regression when the outcome was incidence of dementia; prevalent dementia at the start of follow-up was excluded in all the analyses. Participants were censored at the date of record of dementia, death, or March 31, 2019, whichever came first. Participants who died over the follow-up were censored at date of death to account for competing risk of death using cause-specific hazard models. ${ }^{19,20}$ Proportional hazards assumption was verified by plotting Schoenfeld residuals. Analyses were first adjusted for age, sex, race, education, and birth cohort in 5-year groups (model 1) to account for confounding due sociodemographic characteristics. The analyses were then additionally adjusted for health behaviors (model 2), and in the final model also for CVD, hypertension, BMI, use of antidepressants, and use of CVD medication (model 3).

\section{Association of Type 2 Diabetes With Incident Dementia}

This association was examined according to age at type 2 diabetes onset (at $55,60,65$, and 70 years) with the reference group at each age being participants free of type 2 diabetes at that specific age. At age 55, this implied comparing those with type 2 diabetes at that point or earlier with those free of type 2 diabetes at 55 years and treating diabetes cases after age 55 as nondiabetes cases. Besides diabetes status at ages 55, 60, 65 , and 70 , we also examined diabetes as a time-varying measure. Subsequent analyses at ages 60,65 , and 70 years involved use of 5 -year age bands for the onset of type 2 diabetes. For example, at age 70 years the group defined as having no type 2 diabetes at age 70 was compared with a group diagnosed with type 2 diabetes at 5 or fewer years earlier, 6-10 years earlier, and more than 10 years earlier. A test for trend using diabetes categories as a linear variable was used to examine whether the magnitude of associations of type 2 diabetes with dementia was higher with younger age at diabetes onset. In addition, using diabetes status at age 70, the association between every 5-year younger age at diabetes onset and incident dementia was estimated.

FINDRISC, Fasting Glucose, and Prediabetes in Participants Without Type 2 Diabetes

The shape of the association between continuous measures of FINDRISC, at ages 55, 60, 65, and 70 years and subsequent dementia was plotted using restricted cubic splines with Harrell knots, ${ }^{21}$ using the command mkspline in Stata. In the absence of nonlinearity $(P=.61$ at age $55, P=.16$ at age $60, P=.26$ at age $65, P=.56$ at age 70 ), we examined the association of a 5-point higher FINDRISC score and subsequent dementia using Cox regression.

For analysis of prediabetes, 3 groups were defined: normoglycemic ( $<100 \mathrm{mg} / \mathrm{dL}$ ), prediabetes $(100-125 \mathrm{mg} / \mathrm{dL})$, and type 2 diabetes. Cox regression was used to examine associations with dementia using the normoglycemic group as the reference standard. These analyses were repeated using the World Health Organization threshold to define prediabetes (110-125 $\mathrm{mg} / \mathrm{dL}$ ). The association of fasting glucose levels as a continuous measure between 90 and $126 \mathrm{mg} / \mathrm{dL}$ at a mean (SD) age of 60 (4) years and dementia was examined using restricted cubic splines ${ }^{21}$ with 4 knots. As there was no evidence of nonlinearity ( $P$ value for nonlinearity, .82), the hazard ratio (HR) for $18 \mathrm{mg} / \mathrm{dL}$-higher fasting glucose was estimated.

Type 2 Diabetes, CVD Comorbidity, and Dementia The risk of dementia among participants with type 2 diabetes without CVD was compared with participants who had type 2 
diabetes and CVD comorbidity (CHD, heart failure, and stroke). Participants were followed up from the date at type 2 diabetes diagnosis with cardiovascular comorbidity (individually, 2 of 3 , or all 3) as time-varying covariates.

\section{Additional Analysis}

First, in an alternative approach to take competing risk of mortality into account, the Fine and Gray subdistribution hazard models ${ }^{19,20}$ were used in analysis of the association between age at diabetes onset and dementia. Second, we examined whether the association of type 2 diabetes, treated as a timevarying measure, and incidence of dementia was similar in APOE $\varepsilon 4$ allele carriers and non-carriers by introducing an interaction term between type 2 diabetes and $A P O E$ genotype (coded as no vs $\geq 1$ APOE $\varepsilon 4$ allele).

Because of the potential for type 1 error due to multiple comparisons, findings for secondary analyses should be interpreted as exploratory. Two-sided $P$ values were used with an $\alpha=.05$ threshold for statistical significance. All analyses were undertaken using STATA version 15.1 (StataCorp).

\section{Results}

A total of 10308 persons were recruited to the study in 1985, the numbers in analyses and exclusions are shown in eFigure 1 in the Supplement. Characteristics of 10095 participants in the analyses are presented in Table 1 . The numbers of participants who were categorized as Black, South Asian, and other were small and were combined in the analyses. Between 1985 and 2019, 639 (6.3\%) participants were diagnosed with dementia; these individuals were more likely to have chronic conditions over the follow-up period and to have a worse cardiovascular risk profile at age 60 (Table 1).

Over the follow-up, 1710 participants (16.9\%) developed diabetes, among whom 153 (8.9\%) were subsequently diagnosed with dementia. Cumulative hazards of dementia as a function of diabetes status at ages 55, 60, 65, and 70 years are shown in eFigure 2 in the Supplement. At age 55, the dementia rate per 1000 person-years was 3.14 in participants without diabetes and 5.06 in participants with diabetes; the corresponding fully adjusted HR was 2.14 (95\% CI, 1.44-3.17; eTable 2 in the Supplement). At age 70, the corresponding dementia rate was 8.85 per 1000 person-years in participants without diabetes and 13.88 in participants with diabetes (HR, 1.58 [95\% CI, 1.22-2.03]). As $48.3 \%$ (826 of 1710) of diabetes cases occurred after 70 years of age, all diabetes cases were analyzed by treating diabetes and covariates as time-varying measures. In these analyses, the fully adjusted HR for dementia was 1.40 (95\% CI, 1.15-1.70), and the dementia rates were 1.76 per 1000 person-years in participants without diabetes and 6.25 in participants with diabetes.

Table 2 shows results of age at onset of diabetes. At ages 60,65 , and 70 years, earlier age at diabetes onset was more strongly associated with dementia, as shown by the test for linear trend (all $P<.001$ ). In fully adjusted analyses compared with participants without diabetes at age 65 (dementia rate, 5.70/1000 person-years), diabetes onset from 0 to 5 years ear- lier was significantly associated with subsequent dementia (HR, 1.53 [95\% CI, 1.03-2.29]; dementia rate, 8.63/1000 personyears), as well as diabetes onset 6 to 10 years earlier (HR, 2.03 [95\% CI, 1.48-2.79]; dementia rate, $10.51 / 1000$ person-years). When diabetes status at age 70 was considered, the HR of dementia in participants with diabetes onset more than 10 years earlier was 2.12 (95\% CI, 1.50-3.00 [dementia rate, 18.30/ 1000 person-years]), in participants with diabetes onset 6 to 10 years earlier the HR was 1.49 (95\% CI, 0.95-2.32 [dementia rate, $12.99 / 1000$ person-years]), and in participants with diabetes onset 0 to 5 years earlier the HR was 1.11 (95\% CI, 0.701.76 [dementia rate, $10.00 / 1000$ person-years]). At age 70, every 5 -year younger age at onset of type 2 diabetes was significantly associated with an HR of dementia of 1.24 (95\% CI, 1.061.46) in fully adjusted analyses.

Those with younger-onset diabetes were younger at onset of dementia (eTable 3 in the Supplement). For example, when diabetes status was examined at age 65, the mean (SD) age of dementia diagnosis was 77.5 (5.3) years in participants without diabetes, 76.7 (5.5) years in participants with diabetes onset between 61 and 65 years, and 75.8 (5.5) years in participants with diabetes onset at 60 years of age or younger ( $P$ for linear trend, .02).

In additional analyses, Fine and Gray subdistribution hazard yielded results similar to that in the main analyses (eTable 4 in the Supplement). In the subsample with data on APOE genotype (6069 of 10 095), the fully adjusted HR for the association of diabetes with the incidence of dementia (eTable 5 in the Supplement) in APOE ع 4 carriers was 1.34 (95\% CI, 0.892.00; model 3) and in noncarriers, the HR was 1.39 (95\% CI, 0.99-1.96; model 3) with no significant difference in associations in these 2 groups ( $P$ for interaction, .21; model 3 ).

The association between FINDRISC, adjusted for sociodemographic covariates, and incidence of dementia is shown in the Figure. The HR for every 5-point higher FINDRISC at ages $55,60,65$, and 70 years did not show significant associations with dementia. Prediabetes was not significantly associated with dementia, irrespective of the age at which prediabetes was assessed (Table 3). Use of the World Health Organization threshold to define prediabetes (110-125 mg/dL) did not alter findings (eTable 6 in the Supplement). Further analysis of continuous measure of fasting blood glucose at mean (SD) age of 60 (4 years) in the 90 to $126 \mathrm{mg} / \mathrm{dL}$ range showed an HR of incident dementia of 1.31 (95\% CI, 1.02-1.68) for $18 \mathrm{mg} / \mathrm{dL}$ higher fasting glucose (eFigure 3 in the Supplement). The analyses on prediabetes, fasting glucose, and FINDRISC were based on smaller numbers due to use of data from the clinical examinations, but the association between diabetes and incidence of dementia in this population (Table 3) was similar to that in the total population (Table 2).

The analyses on cardiovascular comorbidity (CHD, heart failure, and stroke) in participants with diabetes $(\mathrm{N}=1710)$ are shown in Table 4. Compared with diabetes alone (75 dementia cases in 992 persons; dementia rate, 5.18/1000 personyears), diabetes accompanied by stroke was significantly associated with higher risk of dementia ( 9 dementia cases in 58 persons; dementia rate, 24.32/1000 person-years; HR, 2.17 [95\% CI, 1.05-4.48]). The HR was 4.99 (95\% CI, 2.19-11.37) in 
Table 1. Characteristics of Participants According to Dementia Status at the End of the Follow-up, March 2019

\begin{tabular}{|c|c|c|}
\hline \multirow[b]{2}{*}{$\begin{array}{l}\text { Participant characteristics } \\
\text { at the end of follow-up }{ }^{a}\end{array}$} & \multicolumn{2}{|c|}{ Dementia status, №. (\%) } \\
\hline & Dementia $(n=639)$ & $\begin{array}{l}\text { No dementia } \\
(n=9456)\end{array}$ \\
\hline Men & $374(58.5)$ & $6424(67.9)$ \\
\hline Women & $265(41.5)$ & $3032(32.1)$ \\
\hline Age, mean (SD), y & $76.8(6.0)$ & $74.6(7.2)$ \\
\hline \multicolumn{3}{|l|}{ Education } \\
\hline$\leq$ Partial secondary school & $378(59.2)$ & $4398(46.5)$ \\
\hline High school diploma & $135(21.1)$ & $2550(27.0)$ \\
\hline zUniversity degree & $126(19.7)$ & $2508(26.5)$ \\
\hline \multicolumn{3}{|l|}{ Race $^{c}$} \\
\hline White & $547(85.6)$ & $8546(90.4)$ \\
\hline South Asian & $47(7.4)$ & $524(5.5)$ \\
\hline Black & $41(6.4)$ & $315(3.3)$ \\
\hline Other & $4(0.6)$ & $71(0.8)$ \\
\hline \multicolumn{3}{|l|}{ Health conditions } \\
\hline Coronary heart disease & $170(26.6)$ & $1920(20.3)$ \\
\hline Diabetes & $153(23.9)$ & $1557(16.5)$ \\
\hline Heart failure & $56(8.8)$ & $520(5.5)$ \\
\hline Stroke & $57(8.9)$ & 373 (3.9) \\
\hline \multicolumn{3}{|c|}{ Risk factors in participants at age 60, No. $(\%)^{d}$} \\
\hline & $(n=633)$ & $(n=9127)$ \\
\hline Hypertension & $256(40.4)$ & 3069 (33.6) \\
\hline \multicolumn{3}{|l|}{ Body mass index } \\
\hline$<25$ & $273(43.1)$ & $3910(42.8)$ \\
\hline $25-29.9$ & $251(39.7)$ & $3782(41.4)$ \\
\hline$\geq 30$ & $109(17.2)$ & $1435(15.7)$ \\
\hline \multicolumn{3}{|l|}{ Smoking } \\
\hline Never & $303(47.9)$ & $4301(47.2)$ \\
\hline Former & $234(37.0)$ & $3688(40.4)$ \\
\hline Current & $96(15.2)$ & $1138(12.5)$ \\
\hline $\begin{array}{l}\text { Moderate and vigorous } \\
\text { physical activity, } \\
\text { mean (SD), h/wk }\end{array}$ & $3.4(4.0)$ & $3.6(3.7)$ \\
\hline \multicolumn{3}{|l|}{$\begin{array}{l}\text { Alcohol consumption, } \\
\text { units/wk }\end{array}$} \\
\hline 0 & $192(30.3)$ & $1772(19.4)$ \\
\hline $1-14$ & $307(48.5)$ & $4857(53.2)$ \\
\hline$>14$ & $134(21.2)$ & $2498(27.4)$ \\
\hline \multicolumn{3}{|l|}{$\begin{array}{l}\text { Fruit and vegetable } \\
\text { consumption/d }\end{array}$} \\
\hline$<1$ & $229(36.2)$ & $2778(30.4)$ \\
\hline 1 & $261(41.2)$ & $3334(36.5)$ \\
\hline$>1$ & $143(22.6)$ & $3015(33.0)$ \\
\hline $\begin{array}{l}\text { Cardiovascular disease } \\
\text { medication }\end{array}$ & $172(27.2)$ & $2275(24.9)$ \\
\hline Use of antidepressants & $23(3.6)$ & $285(3.1)$ \\
\hline
\end{tabular}

${ }^{a}$ Median (interquartile range) overall follow-up was 31.7 (31.1-32.6) years; for participants with dementia, it was 27.6 (24.6-30.2) years, and for participants without dementia, it was 31.8 (31.2-32.7) years at end of follow-up.

b Values are reported as No. (\%) unless otherwise indicated.

${ }^{\mathrm{C}}$ Assessed by questionnaire using the response categories shown in the table. Due to small numbers, values for Black, South Asian, and Other race/ethnicity groups were combined in analyses.

${ }^{d}$ Data on risk factors at age 60 not shown for 335 participants; 6 were excluded due to dementia diagnosis before age 60 and 329 died before age 60 .

e Calculated as weight in kilograms divided by height in meters squared. the presence of all 3 conditions ( 7 dementia cases in 22 persons; dementia rate, 77.77/1000 person-years), although these analyses were based on small numbers.

\section{Discussion}

In this longitudinal study, younger age at onset of diabetes was significantly associated with a higher HR of dementia. Data spanning 35 to 75 years for age of diabetes onset showed every 5 -year earlier onset of diabetes was significantly associated with higher hazard of dementia. Late-onset diabetes was not significantly associated with subsequent dementia. Other key findings include the lack of a robust association of dementia with preclinical diabetes (prediabetes or fasting glucose) or the FINDRISC in participants without diabetes, irrespective of age at assessment. In addition, in individuals with diabetes, stroke comorbidity was associated with additional increased risk of dementia. Taken together, these findings highlight the importance of age at onset of diabetes and cardiovascular comorbidity in persons with diabetes for risk of dementia.

Meta-analyses of the association between type 2 diabetes and dementia reported a risk ratio between 1.43 and 1.62. ${ }^{4-8}$ These estimates are in line with results in the present study of a hazard ratio of 1.52 (model 1 in eTable 2 in the Supplement) when all diabetes cases were considered in the analyses, including those occurring after 70 years of age. The population-attributable fraction of $1.1 \%$ for diabetes in the recent Lancet Commission was based on a risk ratio of 1.5 and prevalence of diabetes at $6.4 \% .{ }^{12}$ Both the risk ratio and the prevalence of type 2 diabetes may not be generalizable. The HR of dementia for diabetes onset at or before age 60 in the present study was 1.99 in fully adjusted analyses. The global prevalence of diabetes is estimated at $15 \%$ at ages 55 to 59 years and at $20 \%$ or greater starting from age $65 .{ }^{22}$ In the UK, prevalence was $19.3 \%$ in $2014 / 2015 .{ }^{23}$ The results of the present study suggest that a population-attributable fraction of $1.1 \%$ in the study by Livingston and colleagues ${ }^{12}$ is likely to be an underestimate, particularly in settings where the prevalence of early onset type 2 diabetes is high.

To date, studies that explicitly consider age at diabetes onset or diabetes duration remain scarce, primarily because studies on dementia recruit participants older than 65 years and age at diabetes onset is not known with precision or not taken into consideration. One exception is the Swedish Twin Registry study in which record of diabetes before 65 years (OR, 2.41 [95\% CI 1.05-5.51]) but not after 65 years (OR, 0.68 [95\% CI, $0.30-1.53]$ ) was associated with higher risk of dementia. ${ }^{24} \mathrm{Re}-$ sults from the US ARIC study, based on persons aged 66 to 90 years at start of follow-up, suggest longer diabetes duration to be associated with higher risk of dementia only in the youngest age tertile. ${ }^{25}$ Longer duration of diabetes has also been associated with faster cognitive decline. ${ }^{26,27}$ Careful analysis of age of diabetes onset in the present study, along with explicit examination of duration of diabetes, showed a graded association between age at onset of diabetes and dementia risk.

Results from previous studies on prediabetes and dementia are inconsistent; a meta-analysis found associations with 
A Aged $55 \mathrm{y}$

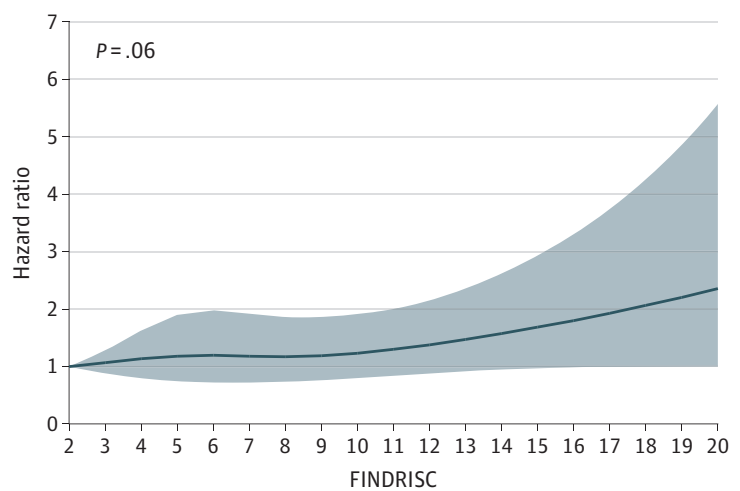

$\begin{array}{lllllllll}2-3 & 4-5 & 6-7 & 8-9 & 10-11 & 12-13 & 14-15 & 16-17 & 18-19\end{array} 220$

No. of patients

$\begin{array}{lrrrrrrrrrr}\text { Without dementia } & 771 & 1815 & 1128 & 1064 & 806 & 424 & 194 & 67 & 24 & 5 \\ \text { With dementia } & 40 & 98 & 89 & 48 & 52 & 26 & 10 & 7 & 3 & 1\end{array}$

C Aged $65 \mathrm{y}$

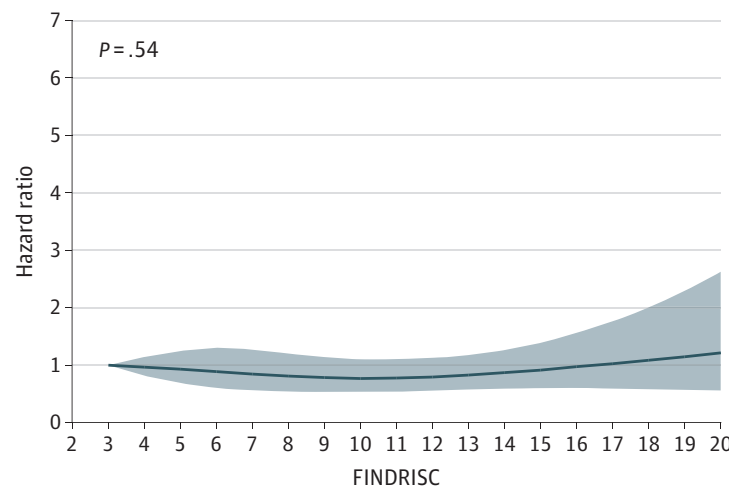

\begin{tabular}{lllllllll}
$2-3$ & $4-5$ & $6-7$ & $8-9$ & $10-11$ & $12-13$ & $14-15$ & $16-17$ & $18-19 \geq 20$ \\
\hline
\end{tabular}

No. of patients

$\begin{array}{llllllllll}\text { Without dementia } 301 & 1107 & 1082 & 988 & 1092 & 640 & 285 & 97 & 53 & 16\end{array}$

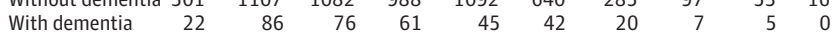

B Aged $60 \mathrm{y}$

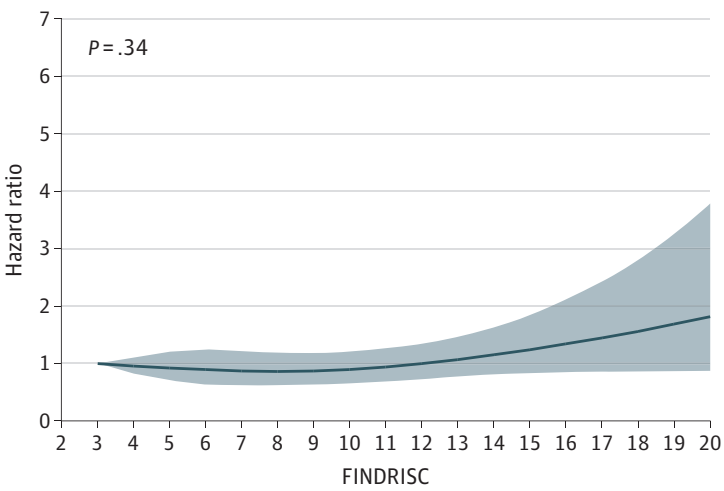

$\begin{array}{lllllllll}2-3 & 4-5 & 6-7 & 8-9 & 10-11 & 12-13 & 14-15 & 16-17 & 18-19\end{array} 220$ $\begin{array}{rrrrrrrrrr}644 & 1454 & 1206 & 1011 & 992 & 584 & 267 & 80 & 33 & 13 \\ 47 & 106 & 84 & 54 & 52 & 44 & 19 & 5 & 2 & 1\end{array}$

D Aged $70 \mathrm{y}$

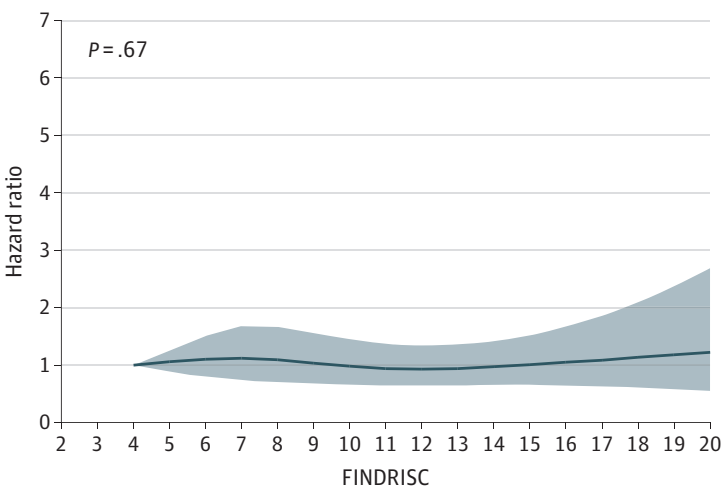

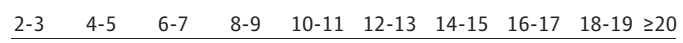
$\begin{array}{llllllllll}0 & 667 & 996 & 828 & 1059 & 693 & 313 & 147 & 55 & 22\end{array}$ $\begin{array}{llrrrrrrr}0 & 42 & 75 & 45 & 58 & 36 & 22 & 5 & 7\end{array}$
Analyses were adjusted for age, sex, race, education, and birth cohort (5-year groups). The gray shading indicates the $95 \% \mathrm{Cl}$. All figures were produced using restricted cubic spline (4 knots) and the untransformed Finnish Diabetes Risk Score (FINDRISC; score range, 0-26 [age, 0-4 points; family history of diabetes, 0-5 points; vegetable and fruit intake, $0-2$ points; physical activity, $0-2$ points; medical treatment of hypertension, 0-2 points; history of high blood glucose, 0-5 points; body mass index, 0-3 points; and waist circumference, $0-4$ points]).
A rating score between 0 and 14 points indicates a low to moderate risk of diabetes, 15 to 20 points indicates a high risk of diabetes, and greater than 20 points indicates a very high risk of diabetes. The hazard ratio (HR) estimates are for a 5-point higher FINDRISC score (for age 55 y: HR, 1.16 [95\% Cl, 0.99-1.35]; for age $60 \mathrm{y}: \mathrm{HR}, 1.08$ [95\% Cl, 0.93-1.25]; for age $65 \mathrm{y}$ : $\mathrm{HR}, 0.95$ [95\% Cl, 0.82-1.11]; and for age $70 \mathrm{y}: \mathrm{HR}, 0.96$ [95\% Cl, 0.82-1.14]. participants and found that the higher risk among those with diabetes could not be attributed to cardiovascular comorbidity on its own. This finding led to use of an analysis strategy in the present study that allowed the examination of risk for 1 or more cardiovascular comorbidities in participants with diabetes. Stroke combined with diabetes was associated with a higher risk of dementia, and the highest risk of dementia was seen in those with stroke, CHD, and heart failure. These results highlight the need to address cardiovascular comorbidity in individuals with diabetes.

The precise mechanisms underlying the association between type 2 diabetes and dementia remain unclear. Further, studies do not always show a consistent association between diabetes and hallmarks of Alzheimer disease, such as amyloid and tau pathology. ${ }^{31}$ Although the histopathological, molecular, and biochemical abnormalities in Alzheimer disease are well characterized, a unified framework that links these features is lacking. There are several possible explanations for the association between type 2 diabetes and dementia. One hypothesis is that brain metabolic dysfunction is the primary driver of Alzheimer disease, ${ }^{32}$ highlighting the role of decreased transport of insulin through the blood-brain barrier, impairments in insulin signaling, and consequently decreased cerebral glucose utilization. ${ }^{33,34}$ Insulin resistance is a key feature of diabetes 


\begin{tabular}{|c|c|c|c|}
\hline & No diabetes & Prediabetes & Diabetes \\
\hline \multicolumn{4}{|l|}{ At age $55 y^{b}$} \\
\hline Follow-up, median (IQR), y & $20.7(15.6-25.8)$ & & \\
\hline Dementia cases/total cases, No. ${ }^{c}$ & $276 / 5175$ & $77 / 1363$ & $30 / 318$ \\
\hline Rate/1000 person-years & 2.72 & 2.89 & 5.45 \\
\hline \multicolumn{4}{|l|}{ Model, HR $(95 \% \mathrm{Cl})^{\mathrm{d}}$} \\
\hline 1 & 1 [Reference] & $1.04(0.81-1.35)$ & $2.16(1.46-3.18)$ \\
\hline 2 & 1 [Reference] & $1.03(0.80-1.34)$ & $2.13(1.44-3.14)$ \\
\hline 3 & 1 [Reference] & $0.99(0.76-1.28)$ & $2.01(1.36-2.97)$ \\
\hline \multicolumn{4}{|l|}{ At age $60 y^{b}$} \\
\hline Follow-up, median (IQR), y & $15.6(10.7-21.0)$ & & \\
\hline Dementia cases/total cases, No. ${ }^{c}$ & $309 / 5137$ & $91 / 1352$ & $42 / 450$ \\
\hline Rate/1000 person-years & 3.75 & 4.15 & 7.06 \\
\hline \multicolumn{4}{|l|}{ Model, HR $(95 \% \mathrm{Cl})^{\mathrm{d}}$} \\
\hline 1 & 1 [Reference] & $1.10(0.87-1.39)$ & $2.36(1.69-3.30)$ \\
\hline 2 & 1 [Reference] & $1.08(0.86-1.37)$ & $2.34(1.67-3.27)$ \\
\hline 3 & 1 [Reference] & $1.05(0.83-1.34)$ & $2.14(1.52-3.01)$ \\
\hline \multicolumn{4}{|l|}{ At age $65 \mathrm{y}^{\mathrm{b}}$} \\
\hline Follow-up, median (IQR), y & $10.6(6.5-15.8)$ & & \\
\hline 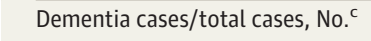 & $277 / 4525$ & $78 / 1166$ & $46 / 586$ \\
\hline Rate/1000 person-years & 5.33 & 6.05 & 7.97 \\
\hline \multicolumn{4}{|l|}{ Model, HR $(95 \% \mathrm{Cl})^{\mathrm{d}}$} \\
\hline 1 & 1 [Reference] & $1.28(0.99-1.65)$ & $1.74(1.26-2.41)$ \\
\hline 2 & 1 [Reference] & $1.27(0.99-1.64)$ & $1.65(1.19-2.29)$ \\
\hline 3 & 1 [Reference] & $1.28(0.98-1.65)$ & $1.60(1.15-2.23)$ \\
\hline \multicolumn{4}{|l|}{ At age $70 y^{b}$} \\
\hline Follow-up, median (IQR), y & $6.5(3.5-10.9)$ & & \\
\hline 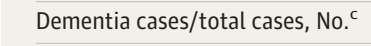 & $199 / 3607$ & $66 / 983$ & $47 / 620$ \\
\hline Rate/1000 person-years & 7.16 & 8.09 & 10.80 \\
\hline \multicolumn{4}{|l|}{ Model, HR $(95 \% \mathrm{Cl})^{\mathrm{d}}$} \\
\hline 1 & 1 [Reference] & $1.06(0.80-1.40)$ & $1.55(1.11-2.15)$ \\
\hline 2 & 1 [Reference] & $1.07(0.81-1.42)$ & $1.47(1.05-2.05)$ \\
\hline 3 & 1 [Reference] & $1.09(0.82-1.45)$ & $1.47(1.04-2.06)$ \\
\hline
\end{tabular}

Abbreviations: CVD, cardiovascular disease; HR, hazard ratio; $\mathrm{IQR}$, interquartile range.

a Prediabetes is defined as (per the American Diabetes Association) fasting blood glucose between $100 \mathrm{mg} / \mathrm{dL}$ and $125 \mathrm{mg} / \mathrm{dL}$ (to convert to $\mathrm{mmol} / \mathrm{L}$, multiply by 0.0555).

${ }^{\mathrm{b}}$ A 5-year range was allowed around the target age to improve numbers in analyses.

c Differences in the number of cases and noncases across age groups are due to death, dementia onset, or participants not reaching the target age at the end of follow-up (March 2019), flowchart in eFigure 1 in the Supplement.

${ }^{\mathrm{d}}$ Model 1 indicates that analysis was adjusted for age, sex, race, education, and birth cohort (5-year groups). Model 2 indicates model 1 adjustment plus adjustment for health-related behaviors (smoking, alcohol consumption, physical activity, and diet). Model 3 indicates model 2 adjustment plus adjustment for CVD (coronary heart disease, heart failure, or stroke), hypertension, body mass index, use of antidepressants, and use of CVD drugs.

\begin{tabular}{|c|c|c|c|c|c|c|}
\hline & $\begin{array}{l}\text { Diabetes } \\
\text { without stroke, } \\
\text { CHD, or heart failure }\end{array}$ & $\begin{array}{l}\text { Diabetes } \\
\text { and CHD }\end{array}$ & $\begin{array}{l}\text { Diabetes } \\
\text { and heart failure }\end{array}$ & $\begin{array}{l}\text { Diabetes } \\
\text { and stroke }\end{array}$ & $\begin{array}{l}\text { Diabetes } \\
\text { and } 2 \text { of stroke, } \\
\text { CHD, or heart failure }\end{array}$ & $\begin{array}{l}\text { Diabetes } \\
\text { with stroke, CHD, } \\
\text { and heart failure }\end{array}$ \\
\hline Dementia cases/total cases, No. & $75 / 992$ & $37 / 435$ & $5 / 50$ & $9 / 58$ & $20 / 153$ & $7 / 22$ \\
\hline Rate/1000 person-years & 5.18 & 8.03 & 22.01 & 24.32 & 23.18 & 77.77 \\
\hline \multicolumn{7}{|l|}{ Model, hazard ratio $(95 \% \mathrm{Cl})^{\mathrm{b}}$} \\
\hline 1 & 1 [Reference] & $0.94(0.63-1.40)$ & $1.57(0.63-3.92)$ & $2.07(1.02-4.22)$ & $1.92(1.16-3.18)$ & $5.36(2.41-11.90)$ \\
\hline 2 & 1 [Reference] & $0.92(0.62-1.38)$ & $1.57(0.63-3.95)$ & $1.99(0.97-4.08)$ & $1.82(1.10-3.03)$ & $5.08(2.26-11.41)$ \\
\hline 3 & 1 [Reference] & $0.96(0.64-1.44)$ & $1.74(0.68-4.42)$ & $2.17(1.05-4.48)$ & $1.98(1.18-3.33)$ & $4.99(2.19-11.37)$ \\
\hline
\end{tabular}

Abbreviations: CHD, coronary heart disease; CVD, cardiovascular disease; HR, hazard ratio.

a All cardiovascular conditions (stroke, CHD, and heart failure) and covariates are entered as time-varying variables in these analyses.

${ }^{\mathrm{b}}$ Model 1 indicates that analysis was adjusted for age, sex, race, education, and birth cohort (5-year groups). Model 2 indicates model 1 adjustment plus adjustment for health-related behaviors (smoking, alcohol consumption, physical activity, and diet). Model 3 indicates model 2 adjustment plus adjustment for hypertension, body mass index, use of antidepressants, and use of CVD drugs. but also dementia, as suggested by the widespread distribution of insulin receptors in the brain. ${ }^{34}$ This assumes that systemic and brain insulin resistance are linked, a hypothesis supported by a recent cross-sectional study on middle-aged adults that reported insulin resistance to be associated with lower re- gional cerebral glucose metabolism, determined using fluorodeoxyglucose positron emission tomography (FDG-PET). ${ }^{35} \mathrm{Im}$ paired peripheral insulin action leads to hyperglycemia, which may affect dementia risk due to glucose neurotoxicity, vascular injury, and accumulation of advanced glycation end 
products. ${ }^{29}$ Another hypothesis highlights the role of microvascular dysfunction, which leads to inflammatory and immune responses, oxidative stress, increased blood-brain permeability, and altered blood flow regulation. ${ }^{36}$ In addition, episodes of hypoglycemia, ${ }^{37}$ particularly in relation to type 2 diabetes treatment using insulin, ${ }^{38}$ are more likely to occur in longer duration diabetes thereby increasing risk of dementia. The pathophysiological changes in dementia unfold over a long period and how diabetes in early and midlife contributes to these processes needs further research.

The strengths of this study include precise measures of diabetes from midlife to old age and the long follow-up for dementia. Ascertainment of dementia in all participants rather than those who continue to participate in the study was possible due to linkage to electronic health records and is likely to yield results that are less affected by selection bias. Undiagnosed diabetes, estimated to be $50 \%$ globally and between $20 \%$ and $35 \%$ in Europe, ${ }^{22}$ was unlikely to be a concern in the present study due to repeated clinical examinations. Furthermore, the availability of a range of covariates via repeated clinical examinations allowed minimization of bias due to confounders.

\section{Limitations}

This study has several limitations. First, the inability to distinguish dementia subtypes precluded estimation of the association of diabetes with Alzheimer disease and major subtypes of dementia such as vascular dementia. Second, participants in longitudinal studies tend to be healthier than the general population; in the present study, rates of diabetes (16.5\%) and dementia $(6.3 \%)$ were lower than the general UK population. While representative studies are necessary for estimating prevalence and incidence of disease, this is not the case when the aim of the analysis is to examine the association between an exposure and an outcome, ${ }^{39,40}$ as shown by the association between diabetes (time-varying exposure) and dementia in the present study (being in the range of previous findings from meta-analyses). Third, data on glycated hemoglobin, a more stable marker of diabetes status, were available only in the later study waves and could not be used for diabetes diagnosis. Fourth, dementia ascertainment was based on linkage to electronic health records rather than an in-person screening. This method is likely to miss milder cases of dementia, but it has the advantage of allowing analysis on everyone recruited to the study rather than only those who continue to participate over the course of the study. Electronic health records used in this study contain information on both health and social care, and have national coverage precluding major bias in estimation of the association between type 2 diabetes and dementia. Fifth, the age of participants at the end of the follow-up (69-89 years) implies that younger participants have not yet reached an age when dementia is more prevalent. Continuing follow-up in the study will allow further examination of the importance of age at onset of type 2 diabetes for dementia.

\section{Conclusions}

In this longitudinal cohort study with a median follow-up of 31.7 years, younger age at onset of diabetes was significantly associated with higher risk of subsequent dementia.

\section{ARTICLE INFORMATION}

Accepted for Publication: March 2, 2021.

Author Affiliations: Epidemiology of Ageing and Neurodegenerative Diseases, Université de Paris, Inserm U1153, Paris, France (Barbiellini Amidei, Fayosse, Dumurgier, Machado-Fragua, Dugravot, Sabia, Singh-Manoux); Department of Cardio-Thoraco-Vascular Sciences and Public Health, University of Padua, Padua, Italy (Barbiellini Amidei, Kivimäki); Cognitive Neurology Center, Lariboisière - Fernand Widal Hospital, AP-HP, Université de Paris, Paris, France (Dumurgier); Department of Epidemiology and Public Health, University College London, United Kingdom (Tabak, Kivimäki, Sabia, Singh-Manoux); Department of Internal Medicine and Oncology, Semmelweis University Faculty of Medicine, Budapest, Hungary (Tabak); Department of Public Health, Semmelweis University Faculty of Medicine, Budapest, Hungary (Tabak); Cardiovascular Research Institute Maastricht (CARIM), Department of Medicine, Maastricht University Medical Centre, Maastricht, the Netherlands (van Sloten).

Author Contributions: Ms Fayosse and Dr Singh-Manoux had full access to all of the data in the study and take responsibility for the integrity of the data and the accuracy of the data analysis. Dr Barbiellini Amidei and Ms Fayosse contributed equally to this article.

Concept and design: Barbiellini Amidei, Dugravot, Sabia, Singh-Manoux.

Acquisition, analysis, or interpretation of data:
Barbiellini Amidei, Fayosse, Dumurgier, Machado-Fragua, Tabak, van Sloten, Kivimaki, Sabia, Singh-Manoux.

Drafting of the manuscript: Barbiellini Amidei, Singh-Manoux.

Critical revision of the manuscript for important intellectual content: All authors.

Statistical analysis: Barbiellini Amidei, Fayosse,

Dumurgier, Dugravot, Sabia.

Obtained funding: Kivimaki, Singh-Manoux.

Administrative, technical, or material support: Singh-Manoux.

Supervision: Barbiellini Amidei, Fayosse, Singh-Manoux.

Conflict of Interest Disclosures: Dr Tabak reported salary supported by grants from the UK Medical Research Council (MRC) (SO11676) and NordForsk (the Nordic Research Programme on Health and Welfare, 75021) during the conduct of the study. Dr van Sloten reported grants from the Netherlands Organization for Scientific Research and the Netherlands Organization for Health Research and Development (VENI research grant 916.19.074) and the Dutch Heart Foundation (2018T025) outside the submitted work. Dr Kivimaki reported grants from the UK MRC (RO24227; S011676), the National Institute on Aging (NIA), National Institutes of Health (NIH) (RO1AG056477; RF1AG062553), NordForsk (70521), and the Academy of Finland (311492) during the conduct of the study. Dr Sabia reported a grant from the French National Research Agency (ANR-19-CE36-0004-01). Dr Singh-Manoux reported grants from $\mathrm{NIH}$
(R01AG056477; RF1AG062553), the UK MRC (RO24227; S011676), and the British Heart Foundation (BHF) (RG/16/11/32334) during the conduct of the study. No other disclosures were reported.

Funding/Support: The Whitehall II study is supported by grants from NIA, NIH (RO1AG056477; RF1AG062553); UK MRC (R024227; S011676); the BHF (RG/16/11/32334); and the Wellcome Trust (221854/Z/2O/Z). Dr Tabak is supported by the UK MRC (SO11676) and NordForsk (75021). Dr Kivimaki is supported by NordForsk (70521) and the Academy of Finland (311492). Dr Van Sloten is supported by the Netherlands Organization for Scientific Research (VENI research grant 916.19.074) and the Dutch Heart Foundation (research grant 2018T025).

Role of the Funder/Sponsor: The NIH, MRC, and $\mathrm{BHF}$ had no role in the design and conduct of the study; collection, management, analysis, and interpretation of the data; preparation, review, or approval of the manuscript; and decision to submit the manuscript for publication.

Additional Contributions: We thank all of the participating civil service departments and their welfare, personnel, and establishment officers; the British Occupational Health and Safety Agency; the British Council of Civil Service Unions; all participating civil servants in the Whitehall II study; and all members of the Whitehall II study team. The Whitehall II Study team comprises research scientists, statisticians, study coordinators, nurses, 
data managers, administrative assistants, and data entry staff, who make the study possible.

\section{REFERENCES}

1. Chatterjee S, Khunti K, Davies MJ. Type 2 diabetes. Lancet. 2017;389(10085):2239-2251. doi: 10.1016/S0140-6736(17)30058-2

2. Sarwar N, Gao P, Seshasai SR, et al; Emerging Risk Factors Collaboration. Diabetes mellitus, fasting blood glucose concentration, and risk of vascular disease: a collaborative meta-analysis of 102 prospective studies. Lancet. 2010;375(9733) 2215-2222. doi:10.1016/S0140-6736(10)60484-9

3. Rao Kondapally Seshasai S, Kaptoge S, Thompson A, et al; Emerging Risk Factors Collaboration. Diabetes mellitus, fasting glucose, and risk of cause-specific death. N Engl J Med. 2011 364(9):829-841. doi:10.1056/NEJMoa1008862

4. Cheng $G$, Huang $C$, Deng $H$, Wang $H$. Diabetes as a risk factor for dementia and mild cognitive impairment: a meta-analysis of longitudinal studies. Intern Med J. 2012;42(5):484-491. doi:10.1111/j. 1445-5994.2012.02758.x

5. Chatterjee S, Peters SA, Woodward M, et al. Type 2 diabetes as a risk factor for dementia in women compared with men: a pooled analysis of 2.3 million people comprising more than 100000 cases of dementia. Diabetes Care. 2016;39(2):300307. doi:10.2337/dc15-1588

6. Zhang J, Chen C, Hua S, et al. An updated meta-analysis of cohort studies: diabetes and risk of alzheimer's disease. Diabetes Res Clin Pract. 2017; 124:41-47. doi:10.1016/j.diabres.2016.10.024

7. Kivimäki M, Singh-Manoux A, Pentti J, et al; IPD-Work consortium. Physical inactivity, cardiometabolic disease, and risk of dementia: an individual-participant meta-analysis. BMJ. 2019; 365:11495. doi:10.1136/bmj.11495

8. Xue M, Xu W, Ou YN, et al. Diabetes mellitus and risks of cognitive impairment and dementia: a systematic review and meta-analysis of 144 prospective studies. Ageing Res Rev. 2019;55: 100944. doi:10.1016/j.arr.2019.100944

9. Sattar N, Rawshani A, Franzén S, et al. Age at diagnosis of type 2 diabetes mellitus and associations with cardiovascular and mortality risks. Circulation. 2019;139(19):2228-2237. doi:10.1161/ CIRCULATIONAHA.118.037885

10. Huo X, Gao L, Guo L, et al. Risk of non-fatal cardiovascular diseases in early-onset versus late-onset type 2 diabetes in China: a cross-sectional study. Lancet Diabetes Endocrinol. 2016;4(2):115-124. doi:10.1016/S2213-8587(15) 00508-2

11. Tancredi M, Rosengren A, Svensson AM, et al. Excess mortality among persons with type 2 diabetes. N Engl J Med. 2015;373(18):1720-1732. doi:10.1056/NEJMoa1504347

12. Livingston G, Huntley J, Sommerlad A, et al. Dementia prevention, intervention, and care: 2020 report of the Lancet Commission. Lancet. 2020; 396(10248):413-446. doi:10.1016/S0140-6736(20) 30367-6

13. Koopman RJ, Mainous AG III, Diaz VA, Geesey ME. Changes in age at diagnosis of type 2 diabetes mellitus in the United States, 1988 to 2000. Ann Fam Med 2005;3(1):60-63. doi:10.1370/afm.214

14. Marmot MG, Smith GD, Stansfeld S, et al. Health inequalities among British civil servants: the Whitehall II study. Lancet. 1991;337(8754):1387-1393. doi:10.1016/0140-6736(91)93068-K

15. Tabák AG, Jokela M, Akbaraly TN, Brunner EJ, Kivimäki M, Witte DR. Trajectories of glycaemia, insulin sensitivity, and insulin secretion before diagnosis of type 2 diabetes: an analysis from the Whitehall II study. Lancet. 2009;373(9682):22152221. doi:10.1016/S0140-6736(09)60619-X

16. Lindström J, Tuomilehto J. The diabetes risk score: a practical tool to predict type 2 diabetes risk. Diabetes Care. 2003;26(3):725-731. doi:10. 2337/diacare.26.3.725

17. Sommerlad A, Perera G, Singh-Manoux A, Lewis G, Stewart R, Livingston G. Accuracy of general hospital dementia diagnoses in England: sensitivity, specificity, and predictors of diagnostic accuracy 2008-2016. Alzheimers Dement. 2018;14(7):933-943. doi:10.1016/j.jalz.2018.02.012

18. Wilkinson T, Ly A, Schnier C, et al; UK Biobank Neurodegenerative Outcomes Group and Dementias Platform UK. Identifying dementia cases with routinely collected health data: a systematic review. Alzheimers Dement. 2018;14(8):1038-1051. doi:10.1016/j.jalz.2018.02.016

19. Austin PC, Lee DS, Fine JP. Introduction to the analysis of survival data in the presence of competing risks. Circulation. 2016;133(6):601-609. doi:10.1161/CIRCULATIONAHA.115.017719

20. Lau B, Cole SR, Gange SJ. Competing risk regression models for epidemiologic data. Am J Epidemiol. 2009;170(2):244-256. doi:10.1093/aje/ kwp107

21. Harrell FE, Jr. Regression Modeling Strategies: With Applications to Linear Models, Logistic Regression, and Survival Analysis. Springer; 2001. doi:10.1007/978-1-4757-3462-1

22. Standl $E$, Khunti $K$, Hansen TB, Schnell $O$. The global epidemics of diabetes in the 21st century: current situation and perspectives. Eur J Prev Cardiol. 2019;26(2_suppl):7-14. doi:10.1177/ 204748731988102

23. Diabetes UK. Facts and Stats. Revised October 2016. Accessed April 6, 2021. https://diabetesresources-production.s3-eu-west-1.amazonaws. com/diabetes-storage/migration/pdf/DiabetesUK_ Facts_Stats_Oct16.pdf

24. Xu W, Qiu C, Gatz M, Pedersen NL, Johansson $B$, Fratiglioni L. Mid- and late-life diabetes in relation to the risk of dementia: a population-based twin study. Diabetes. 2009;58(1):71-77. doi:10 2337/db08-0586

25. Rawlings AM, Sharrett AR, Albert MS, et al. The association of late-life diabetes status and hyperglycemia with incident mild cognitive impairment and dementia: the ARIC study. Diabetes Care. 2019;42(7):1248-1254. doi:10.2337/dc19-0120

26. Rawlings $A M$, Sharrett $A R$, Schneider $A L$, et al. Diabetes in midlife and cognitive change over 20 years: a cohort study. Ann Intern Med. 2014;161(11): 785-793. doi:10.7326/M14-0737

27. Tuligenga $R H$, Dugravot $A$, Tabák AG, et al. Midlife type 2 diabetes and poor glycaemic control as risk factors for cognitive decline in early old age: a post-hoc analysis of the Whitehall II cohort study. Lancet Diabetes Endocrinol. 2014;2(3):228-235. doi 10.1016/S2213-8587(13)70192-X

28. Crane PK, Walker R, Hubbard RA, et al. Glucose levels and risk of dementia. N Engl J Med. 2013;369 (6):540-548. doi:10.1056/NEJMoa1215740

29. Hamed SA. Brain injury with diabetes mellitus: evidence, mechanisms and treatment implications. Expert Rev Clin Pharmacol. 2017;10(4):409-428. doi:10.1080/17512433.2017.1293521

30. Wang Z, Marseglia A, Shang Y, Dintica C, Patrone $\mathrm{C}, \mathrm{Xu} \mathrm{W}$. Leisure activity and social integration mitigate the risk of dementia related to cardiometabolic diseases: a population-based longitudinal study. Alzheimers Dement. 2020;16(2): 316-325. doi:10.1016/j.jalz.2019.09.003

31. Beeri MS, Bendlin BB. The link between type 2 diabetes and dementia: from biomarkers to treatment. Lancet Diabetes Endocrinol. 2020;8(9): 736-738. doi:10.1016/S2213-8587(20)30267-9

32. Cunnane SC, Trushina E, Morland C, et al. Brain energy rescue: an emerging therapeutic concept for neurodegenerative disorders of ageing. Nat Rev Drug Discov. 2020;19(9):609-633. doi:10.1038/ s41573-020-0072-x

33. Kellar D, Craft S. Brain insulin resistance in Alzheimer's disease and related disorders: mechanisms and therapeutic approaches. Lancet Neurol. 2020;19(9):758-766. doi:10.1016/S1474-4422 (20)30231-3

34. Arnold SE, Arvanitakis Z, Macauley-Rambach SL, et al. Brain insulin resistance in type 2 diabetes and Alzheimer disease: concepts and conundrums. Nat Rev Neurol. 2018;14(3):168-181. doi:10.1038/nrneurol 2017.185

35. Willette AA, Bendlin BB, Starks EJ, et al. Association of insulin resistance with cerebral glucose uptake in late middle-aged adults at risk for Alzheimer disease. JAMA Neurol. 2015;72(9):10131020. doi:10.1001/jamaneurol.2015.0613

36. van Sloten TT, Sedaghat $S$, Carnethon MR, Launer LJ, Stehouwer CDA. Cerebral microvascular complications of type 2 diabetes: stroke, cognitive dysfunction, and depression. Lancet Diabetes Endocrinol. 2020;8(4):325-336. doi:10.1016/S22138587(19)30405-X

37. Yaffe K, Falvey CM, Hamilton $N$, et al; Health ABC Study. Association between hypoglycemia and dementia in a biracial cohort of older adults with diabetes mellitus. JAMA Intern Med. 2013;173(14): 1300-1306. doi:10.1001/jamainternmed.2013.6176 38. McMillan JM, Mele BS, Hogan DB, Leung AA. Impact of pharmacological treatment of diabetes mellitus on dementia risk: systematic review and meta-analysis. BMJ Open Diabetes Res Care. 2018;6 (1):e000563. doi:10.1136/bmjdrc-2018-000563

39. Rothman KJ, Gallacher JE, Hatch EE. Why representativeness should be avoided. Int J Epidemiol. 2013;42(4):1012-1014. doi:10.1093/ije/ dys 223

40. Batty GD, Shipley M, Tabák A, et al. Generalizability of occupational cohort study findings. Epidemiology. 2014;25(6):932-933. doi: 10.1097/EDE.0000000000000184 